\title{
The Role of Institute Level Support Teams on Addressing Barriers to Learning and Provide Support in Schools. Are They Functional?
}

\author{
Jacomina Motitswe \\ Department of Inclusive Education, University of South Africa (UNISA), P.O. Box 392 Pretoria 0003 \\ motitjmc@unisa.ac.za
}

\section{Doi:10.5901/mjss.2014.v5n8p259}

\begin{abstract}
Inclusive Education was adopted as a global strategy for addressing the learning needs of all vulnerable and marginalised learners at the Salamanca World Conference on Special Needs Education in Spain in 1994. The message from the Salamanca statement was not focusing on fitting the learner into the school system, but on critiquing and changing the system itself or its relationship to social justice and equity in an attempt to accommodate the unique and diverse learning needs of all learners (Ainscow, 2004). When the Education White Paper was published in 2001, it was with great anticipation that within the first 5 years all the systems would have been put in place for the full- range scale implementation of an inclusive education system at all levels within a period of twenty years (Schoeman, 2012). The education White Paper 6 came up with strategies of transferring all aspects of the education system such as improving special schools by converting them to resource centres, developing full-service schools, and establishing institute level support teams and District based support teams to provide coordinated professional support services. In accordance to the White paper 6 ( DoE, 2001) all schools are expected to have functional Institute level support teams which comprise of school management, educators, parents or caregivers, community members and learners where applicable. The role of the ILST as envisaged by the White Paper 6 is to ensure an enabling environment for teaching and learning, to provide support programmes for addressing barriers to learning. The aim of the study was to investigate the functionality of the ILST in an inclusive school. A qualitative research approach was done whereby observation, focus group interview and document analysis were used to collect data. The results showed that the ILST still need an intensive and critical training on inclusive practices to provide support services and to address barriers to learning.
\end{abstract}

Keywords: Barriers to learning; Institute level support team; Inclusive Education; Full-service school.

\section{Introduction}

Inclusive Education was adopted as a global strategy for addressing the learning needs of vulnerable and marginalized learners at the Salamanca world conference on Special Needs Education in Spain in 1994 (UNESCO, 1994). The message from the Salamanca statement was not focusing on fitting the learner into the school system, but on critiquing and changing the system itself or its relationship to social justice and equity in an attempt to accommodate the unique and diverse learning needs of all learners (Ainscow, 2004). In keeping up with the trends in inclusive education worldwide, the South African Department of Education (DoE) has introduced the Education White Paper 6 on Special Needs Education: Building an Inclusive Education and Training system, 2001, which is a legislative and policy framework that addresses the building of a single, inclusive system of education that is based on the principles of social justice for all learners, human rights, a healthy environment, participation, social integration and redress, equal and equitable access to education, community responsive and cost effectiveness (DoE, 2001). Inclusive education is defined as a dynamic process of addressing and responding to the diversity of needs of all learners by reducing barriers to and within the learning environment, and of seeing individual differences not a problems but as opportunities for enriching learning (DoE, 2001). It is therefore important that every school should have a support structure which will address these diverse learning needs.

The EWP 6 ( DoE, 2001) introduced education support services within the institutions and district offices in order to reduce the barriers to learning within the education system, these services are called the Institute level support teams (ILST) and the District- based support teams (DBST). These teams are established by institutions in general, further and higher education, as institution-level support mechanism whose primary function is to put in place co-ordinated school, learner and educator support services (SIAS, 2008).

Is it reported that the functionality of the ILST is a prerequisite for a learning support and the EWP6 (DoE, 2001) envisage both the ILST and the DBST as support mechanisms for the education system. Reviews have found that these 
teams are not adequately skilled to provide curriculum, assessment and instructional support in the form of illustrative learning programmes, learner support materials and equipment, assessment instruments and professional support for teachers at all types of school level (Schoeman, 2012). The aim of the study was to explore the effectiveness of the functionality of the ILST in inclusive schools in the Bojanala district at the North West Province in South Africa.

\section{Literature Review - Inclusion}

Inclusion acknowledges and celebrates all aspects of differences and seeks to create schools that welcome all learners ensuring that they reach the expected education needs of all (Pienaar \& Raymond, 2013). The philosophy of inclusion in the South African Education system is rooted in the country's Constitution ( South Africa, 1996a), which itself is grounded in the values of human dignity, the achievement of equality and the advancement of human rights and freedom (South African Schools Act $\{S A S A\}, 1996 \mathrm{~b}: 34)$. For that reason, the move towards inclusion in the country's education system has aimed at maximizing the participation of all learners in the curriculum and developing them to become fully functioning citizens who can participate meaningfully in the country's economy, and be able to compete globally.

Inclusion also focuses more on contextual factors as to how these interfere with teaching and learning process than on what is wrong with the learner. Inclusive education is therefore influenced by the Bronfenbrenner's (1979) ecological model, and it acknowledges that individuals are in constant interaction with various systems in their social environments (Ntombela \& Raymond, 2013). It is acknowledged that the learning and development of learners are influenced by a wide range of factors. These include the learners' biological and psychological systems as well as a number of overlapping contexts that individuals experience.

\subsection{The role of Institute level support team}

The role played by the ILSTs seemed to be in most schools in South Africa. At school level, there should be support structures that guide and support inclusive teaching and learning process. According to the EWP6 (DoE, 2001), the ILST should be centrally involved in identifying 'at risk' and vulnerable learners in the learning process so as to support them (Nel, Nel \& Lebeloane, 2012). In accordance with the EWP6 (DoE, 2001), all schools are expected to have functional ILST to ensure an enabling environment for teaching and learning and to provide support programmes for addressing barriers to learning. Landsberg, Krüger \& Swart (2005) clearly mention that the composition of the ILST will depend on the size and needs of each school and the number of teachers available.

The main function of the ILST is to support the teaching and learning process by identifying and addressing the learners, the teachers and the institutional needs. The team consists of the principal as the ex officio, the head of department (HOD) per phase, (one foundation phase and one intermediate phase), teachers who have specialised skills, guidance and counseling, a representative from the school assessment team and a learner support teacher. However, literature has shown that there is still lack of direction and guidance on these teams function and their composition from one school to the other. There is also lack of knowledge and skills among teachers to support learners who experience barriers to learning including disabilities.

DBST and ILST have attended workshops on National Strategy on Screening, Identification, Assessment and Support (SIAS) which aims at offering guidelines on how to screen, identify, assess and support learners who experience barriers to learning, including those with disabilities, and thereby improve the teaching and learning environment for maximum participation by all learners (DoE, 2008). At most schools there are ILST established according to the EWP 6 (2001), but in some schools these teams are not functional and the members who are selected do not have knowledge and skills on guidance and learner support even though the workshops were attended.

The role of the ILST as envisaged by the EWP6 (DoE, 2001) is to liaise with the DBST and other relevant support providers. The team should identify the learners, teachers and school's needs with regard to barriers to learning and establish an inter- sectoral committee which consist of relevant stakeholders such as health, social services, community, safety and security, child's protection unit and therapists and organise in-service training for teachers in order to support them (DoE, 2005).

It has been more than 12 years since the Inclusive Education Policy was introduced and implemented, but research has confirmed that the implementation is not effectively implemented because of inadequate skills and knowledge of teachers on addressing barriers, teacher do not have skills and knowledge to practice inclusive pedagogies in their classrooms (Schoeman, 2012). The focus of the study was on the following aspects:

- How do ILST function in inclusive primary schools?

- What gets in the way of the ILST to be effectively functional? 
- What need to be done to improve the functionality of the ILST?

\section{Theoretical Framework}

The study adopted the Bronfenbrenner's (1979) systemic theory because it provides a valuable contribution for understanding the support services of learners, teachers and institution and the challenges of addressing social issues and barriers experienced to learning. In provision of learning support, cognisance has therefore been taken of all factors as they relate within the school as a system. (Dreyer, 2010). Addressing the provision of learning support from an ecosystemic perspective provided insight into understanding the development of learners, holistically and in context. It provided the insight into understanding the classrooms and schools by viewing them as systems in interaction with broader social context (Donald, Lazarus, \& Lolwana, 2011).

The ecological systems theory was also relevant to this study because it points out that children live in a certain socio-cultural environment which has an influence on their development. It emphasises the interaction between an individual's development and the systems within the general social context (Mahlo: 2011). Swart \& Pettipher (in Landsberg, Kruger and Nel, 2005), assert that the theory explains the direct and indirect influences on the child's life on four levels namely, micro system, which is the immediate environments in which an individual develops, characterised by those individuals and events closest to one's life, and involving continual face to-face contact, with each person reciprocally influencing the other for example, family, friends, teachers and interpersonal relationships. The meso system refers to the interaction and relationship that develops and exist between the home, the school and the district level. In this case the district- based support team is responsible to monitor, support, evaluate and build capacity in schools. The primary function is to support learning and teaching processes by identifying and addressing barriers to learning through establishing the ILST. The district based support team (DBST) and the ILST would be required to provide the curriculum, assessment and support in the form of learning programmes, learner support materials and professional support for educators.

The exo-system comprises of experiences in which the child does not have an active role, but which influence the other people in the child's life (Swart and Pettipher, 2005). Some of the problems and challenges were identified such as parents' work place, community organisation, resources, either human or financial that may not be available and may delay service delivery to the province, for example, lack of specialised human resources such as learner support educators for full-service schools, school based psychologists, speech therapists, and lack of education devices for learners who have physical disabilities.

The macro system is defined as the culture in which the children live, for example, the behaviour, patterns, beliefs, language and all other products of a group of people that are passed from generation to generation (Swart and Pettipher, 2005). The macro system refers to the national department of education in making policies and legislations and providing provinces with guidelines to implement them according to their needs.

\section{Research Methodology}

A qualitative research approach and purposeful sampling was used. A case study was used at two schools, a full-service and mainstream school to explore the effectiveness of the functionality of the ILST in inclusive schools. Creswell (2003:15) describes a case study as a way in which the researcher explores in depth a programme, event, activity or one or more individuals. De Vos, Strydom, Fouche \& Delport (2011:272) concurs that it aims to gain an in-depth understanding of a practice or issues to facilitate informed decision-making, i.e., it examines a "bounded" (single) entity or phenomenon, over a specific time. I therefore sought to gain an in-depth understanding of the case study, of how support is provided to the learners, teachers and the schools' needs on barriers to learning. The reason for doing a case study of two schools is that each school has its own context of learning support according to level of barriers to learning. The EWP6 (DoE, 2001) introduced three types of schools in order to effectively implement Inclusive Education. These schools are mainstream schools, which cater for mild to moderate barriers to learning; full-service schools, which cater for mild to high level of support needs and are also resource centers for neighbouring mainstream schools; and special schools which are resource centers for both full-service and mainstream schools.

The study was done in the North West Province in the Bojanala Region. Data collection methods included focus group interviews with two groups of the ILSTs, which represented both schools. An interview schedule was used to guide the interviews; open- ended questions were used to allow the members to express their views freely. Individual interview was conducted with the school principals from both schools. Documents such as the ILSTs' portfolios of evidence, individual portfolios as per their roles in the team and documents and reports from District office and DBST were also 
analysed.

\section{Findings and Discussions}

This section reports on the findings of the functionality of the Institute level support teams at two a full-service school and a mainstream school. The following are the themes that emerged during data analysis:

\subsection{The role of the ILST}

The schools where the study took place do have established ILST. Two focus group interviews were done with both teams from the schools, documents were analyzed and the principals were interviewed individually. Both teams mentioned that they were officially elected by the staff members and some of them attended workshops on Learners with special educational needs (LSEN) and SIAS.

It was indicated that both schools have developed the Inclusive Education policy which guides them on learner admission, identifying and addressing barriers to learning, and supporting both the learners and the teachers in terms of teaching and learning needs. The policy also indicated the intervention strategies and developing individualized education program (IEP) for learners who experience barriers to learning. But there were contradictions in the documents with regard to what the policy stated in terms of supportive programmes, especially in terms of the IEPs, there were no evidence of the IEP at the mainstream school, but when reading the intervention forms that were attached, some learners were supposed to have had the IEPS so that they could be provided with a choice, flexibility, on- going assessment including the alternative assessment as a means of differentiating the activities to suit their level of abilities, as well as creativity in differentiating the concepts being taught. The intervention strategies also did not adhere to what was stated in the policy, whereby intervention was seriously done during the finalizing of the progress report schedules to be submitted to the district offices. There was no proof of parental intervention signatories and most of the comments were that the parents did not respond. One could argue that if parents did not respond to the intervention programme, what did the team do to intervene or to involve the parents?

There was proof of intervention programmes and the IEPs for some learners at the full-service school, but the interval dates in between the activities provided for each learner raised questions on why did it took four to six months to intervene or to provide support to some learners? During the interview the team argued that they do not get feedback and support from relevant support providers such as from health, social welfare and mostly the DBST, which make them end up leaving some cases unattended. They indicated that they usually meet once per term with all the educators to discuss the intervention programme and how the educators should do the intervention programme in their classrooms and how to support learners who experience barriers to learning in all the learning areas. The members indicated that if there is no progress during intervention then the educators refer those learners to the ILST to intervene and they develop Individualised Education Program (IEP) for those learners to provide individual support to them. The ILST indicated that they liaise with the District based support team (DBST) in terms of severe cases and they work cooperative with them to refer the learners who have severe barriers to learning to the relevant institution. This was supported by the documents that were analysed which indicated gaps in terms of screening, identification, assessment and support (SIAS) because the comments made by the DBST during monitoring at the school indicated that there were some missing support documents as evidence that the educators were implementing what they were supposed to. When the researcher asked about the comments, the ILST mentioned that they did not understand the strategy on SIAS and still need workshop on identifying and addressing barriers to learning.

Both teams raised a concern that most teachers do not corporate in terms of identifying barriers to learning in their classrooms and that not enough proof is provided if they do identify and address the barriers. This was supported during document analysis because there was limited evidence of learners' IEPs, proof from doctors, social services, police, and interview records with parents especially that were done at the full-service school. The data from the focus group interviews and document analysis show that the teams are not active in identifying and addressing barriers to learning at their respective schools as stated in the EWP 6 (DoE, 2001).

\subsection{Work load}

The members from both focus group interviews indicated that they are not only responsible for addressing barriers to learning, but also class teachers and participate in extra-curricular duties. It was mentioned that ILST meetings are not attended as scheduled due to commitments on other school related responsibilities. The members from the full-service 
school mentioned in details about the administrative work that they go through, which is demanded by the DBST whereas they do not provide them with feedback and enough support so that they can be able to support the learners, teachers and the school in addressing teaching and learning needs.

\subsection{Lack of collaboration with other stakeholders}

All the members raised concern that they try by all means to collaborate with other stakeholders such as health, social, police, child protection, and therapists, but they do not get the support or sometimes do not get feedback from them. When referring learners to therapists, parents have sometimes to pay for consultation because the schools do not have therapists. This is another barrier to both parents and the learners because most parents are unemployed and depend on the learners' social grants.

One principal indicated that instead of being collaborative forum with other teachers within the school in order to support one another to provide support to teaching and learning process as proposed by the EWP 6, some members in the ILST feel that they are responsible for giving all the advice.

The other principal indicated that he is the driving force behind the ILST; some feel that the principal as the authoritative figure in the school should have the most significant role to play in ensuring effective learning support forgetting that he has a lot of work as a manager.

\subsection{Lack of support from DBST}

The ILST members indicate that they do not get enough support from the DBST, whereby they fail to provide support to learners who experience severe barriers to learning to be referred to relevant institutions. This statement was supported by the documents that were analyzed, there was a gap in dates of visits by the DBST; some reports indicated only the areas of development on the Individual learners' support plans but no interventions or recommendations were done by the DBST to guide or to provide support. This also serve as an add on barrier to those learners and teachers.

\section{Conclusion}

Effective collaboration among professionals within a school system or within schools and other stakeholders to address the diverse needs of the learners and teachers can contribute significantly to the effective functionality of the ILST. However, although the schools have established the ILST's the data revealed that they do not function effectively; it showed that meetings were held irregularly. They are not working collaboratively for the best possible solution to address barriers to learning, but they are experienced as referral teams to withdraw learners who experience barriers to learning from mainstream schools without proper support.

\section{Recommendations}

To ensure effective functionality and sustainability of the ILST it is important that continued and quality support and development should be provided to schools.

Each school should be contextualized according to its needs to provide relevant support and professional development that suits them. The School Improvement Plan (SIP) and Teachers developmental plans should be considered.

An effective and well-functioning DBST is a prerequisite if the ILST's is intended to be a team that collaboratively coordinates learner and teacher support services in schools. However, the ILST should not only depend on the DBST for support. They should form an inter sectoral collaborating team with relevant stakeholders to address barriers to learning and to provide support to learners, teachers and the institutions.

\section{References}

Ainscow, M. (2004). Concepts of inclusion. In Inclusive education a framework for reform. Edited by Heung, V. \& Ainscow, M. Hong Kong: Hong Kong Institute of Education, 1-15.

Bronfenbrenner, U. (1979) The ecology of human development: experiments by nature and design. Cambridge, MA: Harvard University Press.

Creswell, J.W. (2003). Research design: Qualitative and quantitative Approaches. California: Sage. 
Department of Education. (2001). Education White Paper 6: Special needs Education. Building an Inclusive Education and Training System. Pretoria: Government Printer.

Department of Education. (2005) Conceptual and operational guidelines for the implementation of inclusive education: District-Based Support Team. Pretoria: Government Printer.

Department of Education. (2008) Operational Manual to the National strategy on screening, identification, assessment and support. Pretoria: Government Printer.

De Vos, A.S. ; Strydom, H. ; Fouche, C.B. \& Delport, C.S.L. (2011). Research at grassroots. 4th edition. Pretoria: Van Schaik.

Donald, D.; Lazarus, S. \& Lolwana, P. 2010. Educational Psychology in Social Context. Cape Town: Oxford press.

Dreyer, L M. (2010) Creating effective schools through collaborative support. Paper presented at the International symposium on Eucational Reform (ISER)

Landsberg, E, Krüger, D, Nel, E (2005). Addressing barriers to learning. Pretoria: Van Schaik.

Mahlo, F D. (2011). Experiences of learning support teachers in the foundation phase, with reference to the implementation of Inclusive Education in Gauteng. DEd Thesis, University of South Africa. Pretoria.

Ntombela, S \& Raymond, E. (2013). In Pienaar, CF. \& Raymond, E. Making Inclusive Education work in classrooms. Pearson. SA.

Pienaar, C.F. \& Raymond, E. (2013) Making Inclusive Education work in classrooms. Pearson. SA.

Schoeman, M. (2012). Developing an inclusive education system: changing teachers' attitudes and practices through critical professional development. Paper presented at the National Teacher Development Conference at the University of Pretoria.

South Africa. (1996a). The South African Constitution and Bill of Rights. Pretoria: Government Printer.

South Africa. (1996b). South African Schools Act 84 of 1996. Pretoria: Government Printer.

Swart, E \& Pettipher,R. (2005). A framework for understanding inclusion. In E. Landsberg, E; Krüger, D \& Swart, E (Eds.). Addressing barriers to Learning South African perspective. Pretoria: Van Schaik.

UNESCO. (1994). The Salamanca Statement and Framework for Action on Special Needs Education. Paris: UNESCO.

UNESCO. (2005). Understanding and Responding to Children's Needs in Inclusive Classrooms: A Guide for the Teachers. Paris: UNESCO. 